06

\title{
Физико-химические процессы, сопровождающие локализацию пластической деформации при импульсном нагружении
}

\author{
(c) С.Н. Буравова, И.С. Гордополова, Е.В. Петров \\ Институт структурной макрокинетики и проблем материаловедения им. А.Г. Мержанова РАН, \\ 142432 Черноголовка, Россия \\ e-mail: svburavova@yandex.ru
}

Поступило в Редакцию 29 мая 2020 г.

В окончательной редакции 14 июля 2020 г.

Принято к публикации 17 июля 2020 г.

Исследование развития деформаций при импульсном нагружении показало определяющую роль мощных ультразвуковых колебаний образца в режиме стоячих волн. Определено влияние массопереноса атомов и ультратонких частиц упрочняющей фазы из матричного материала в зону откольной повреждаемости на микроструктуру деформационных полос. Быстрое охлаждение металла внутри полос локализации, размер которых не превышает нескольких десятков микрон, свидетельствует о том, что изменения фазового состава происходят в результате холодной деформации.

Ключевые слова: ударная волна, разгрузка, локализация деформации, массоперенос, фрагментация, ультразвук.

DOI: $10.21883 /$ JTF.2021.03.50523.186-20

\section{Введение}

Процесс локализации деформации сопровождает практически все ударные и взрывные воздействия на материал и проявляется в виде образования полос некристаллографического сдвига с большой локальной деформацией и интенсивной генерацией дефектов кристаллической структуры. Основная масса работ по изучению полос локализованной деформации (ПЛД) относится к материаловедческому аспекту, что объясняется наличием хорошей измерительной техники. Несмотря на высокий уровень описания эффектов, происходящих с веществом при импульсном нагружении, причины, их вызывающие, остаются не известными, поскольку изучаются сохраненные образцы после взрывного нагружения. Соотношение между структурой образца, развивающейся в процессе деформирования и после деформации, может быть неоднозначным. Авторы работ $[1,2]$ отмечают, что в настоящее время нет представлений о механизме зарождения и развития процесса локализации деформации, отсутствует общее представление о зависимости критических параметров начала локализации от исходных структур. Общепринятая термомеханическая модель локализации деформации Зинера-Холломона, основанная на тепловом разупрочнении, ответить на поставленные вопросы не может. Найти корреляцию между образованием полос локализации, физико-механическими свойствами материала и условиями нагружения в рамках этой модели не удается. В то же время механики, исследующие сам процесс импульсного взаимодействия, не располагают аналогичным оборудованием. По мнению авторов работы [3], физическая интерпретация данных явлений часто оказывается далекой от действительности. В настоящее время сложилась такая ситуация в области изучения реакции материала на ударное нагружение.

Тем не менее прогресс в изучении достигается благодаря структурным исследованиям, и известно уже многое: материал внутри ПЛД подвергается фрагментации [4], химические реакции в ПЛД проявляются в виде окисления фрагментов металлов $[5,6]$; карбидизации перлита и образования глобулярного цементита $[7,8]$; растворения частиц легирующей фазы $[9,10]$. Экспериментально обнаружена миграция частиц (ультратонкие частицы упрочняющей фазы, атомы внедрения и замещения, примесные элементы) из матричного материала к местам развития ПЛД, которая была названа эффектом самозалечивания [6].

Впервые в работах $[11,12]$ было показано, что причиной локализации деформации является высокоскоростное растяжение материала, а не тепловое разупрочнение. В условиях взрывного нагружения ПЛД возникают в зоне интерференции волн разгрузки, где растягивающие напряжения по величине не превышают динамическую прочность. Определяющим фактором возникновения полос локализации оказалась геометрическая форма образца, грани которого являются источником волн разгрузки, что делает понятным, почему не удавалось установить связь образования ПЛД с характеристиками материала и условиями нагружения образца. Откольная природа полос локализации была доказана многочисленными экспериментами [13], что позволило сформулировать их условия зарождения и развития, т.е. решить те проблемы, которые не смогла решить термомеханическая модель локализации.

Рассмотрение волновой картины возникновения ПЛД с учетом сжимаемости вещества привело к установлению процесса осцилляции образца [8]. Ультразвуковые 
колебания являются следствием откольной природы локализации и возникают в образцах ограниченных размеров как результат отражения волн на гранях образца и взаимодействия отраженных волн между собой. Факт возникновения реверберации при локализации деформации ранее известен не был.

Учитывая общее состояние проблемы локализации деформации при ударных нагрузках, в настоящей работе делается попытка на основе экспериментов и известных литературных данных объяснить особенности протекания физико-химических процессов, имеющих место в полосах локализации под влиянием ультразвуковых колебаний и массопереноса ультратонких частиц к местам откольной повреждаемости.

\section{1. Миграция частиц к местам откольной повреждаемости}

Под частицами подразумеваются атомы внедрения, замещения, примесные элементы, ультратонкие частицы упрочняющей фазы.

\section{1. Глобулизация цементита и массоперенос углерода}

Изучение микроструктуры полос локализованной деформации проводилось с использованием традиционного метода нагружения цилиндрического образца ударом пластины (рис. 1), разогнанной зарядом взрывчатого вещества - аммонитом 6ЖВ со скоростью детонации $4.62 \mathrm{~km} / \mathrm{s}$ или зарядом литого тротила со скоростью детонации $6.7 \mathrm{~km} / \mathrm{s}$. В качестве материала образца использовалась конструкционная сталь Ст. 3 с исходной ферритно-перлитной структурой в состоянии поставки, цементитные пластины в перлите стального образца имели размер $2-3 \mu \mathrm{m}$.

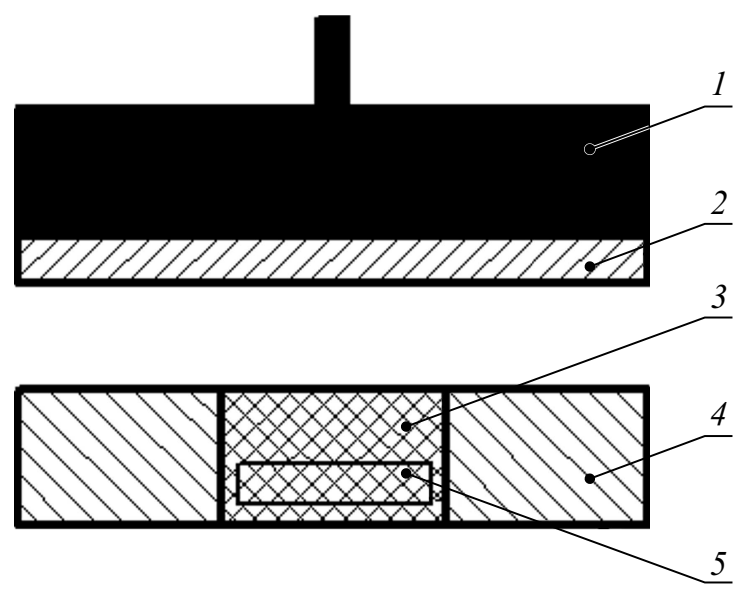

Pис. 1. Схема эксперимента: 1 - заряд взрывчатого вещества, 2 - пластина-ударник, 3 - образец, 4 - обойма, 5 - область торцевой повреждаемости (откольная трещина, множественный откол или полосы локализованной деформации).

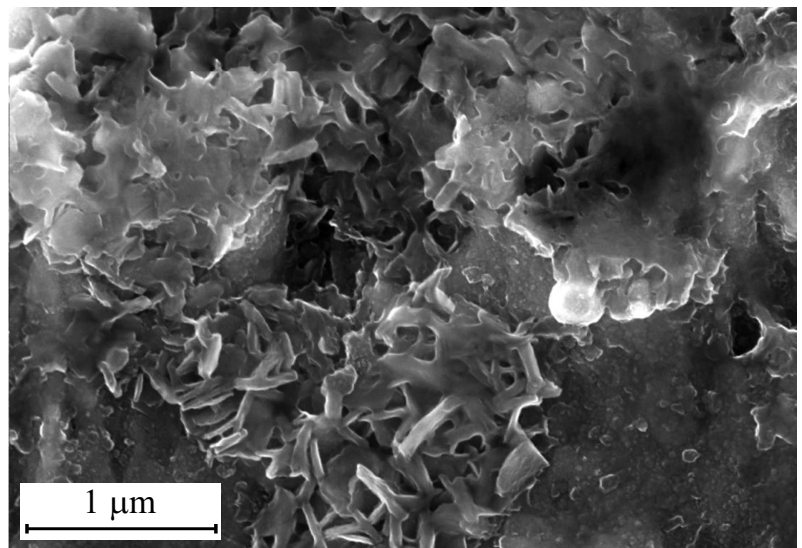

Рис. 2. Микроструктура стали 3 в полосе локализованной деформации. Пластина-ударник разгонялась зарядом аммонита $6 Ж В$.

Исследование микроструктуры ПЛД проводилось на сканирующих электронных микроскопах Zeiss Ultraplus, Leo 1450VP и универсальном металлографическом микроскопе Axiovert $200 \mathrm{MAT} / \mathrm{M}$.

Рис. 2 демонстрирует участок полосы локализации в области контакта пластин цементита и феррита. В процессе формирования ПЛД металл подвергается фрагментации: пластины цементита дробятся. Характерно, что часть осколков сохраняют четкие контуры, и их размер составляет $0.2-0.5 \mu \mathrm{m}$. Размытие краев пластин цементита, наблюдаемых в основном вблизи полос феррита, свидетельствует о разложении цементита. Многочисленные темные и серые области на рис. 2 - это феррит. Известно, что между углеродом и дислокациями существует сильное взаимодействие [14], углерод способен оседать на дислокациях, закреплять и ограничивать их движения.

При изучении механизма распада цементита в процессе пластической деформации в диапазоне температур от -196 до $+20^{\circ} \mathrm{C}$ [15] была установлена корреляция явления распада цементита с характером распределения дислокаций. Распад частиц при взаимодействии их с дислокациями имеет место, когда энергия связи атомов внутри частиц меньше, чем энергия связи этих частиц с дислокациями. Экспериментально наблюдаемый эффект распада цементита в сильнодеформированной стали достигает 30-40\% [15]. Как возможный механизм распада рассматривалась диффузия (дрейф) атомов углерода из частиц цементита в феррит в поле напряжений дислокаций и вынос атомов углерода при перерезании частиц дислокациями.

Обращает внимание наличие сферической яркой частицы на рис. 2, которая образовалась на размытой границе цементита с ферритом. Ранее глобулярный цементит в полосах адиабатического сдвига (ПЛД) был обнаружен в экспериментах при динамическом кручении на установке Гопкинсона при давлении $0.1-0.3 \mathrm{GPa}$ и длительности воздействия до $100 \mu \mathrm{s}$ [7]. Тонкий гло- 


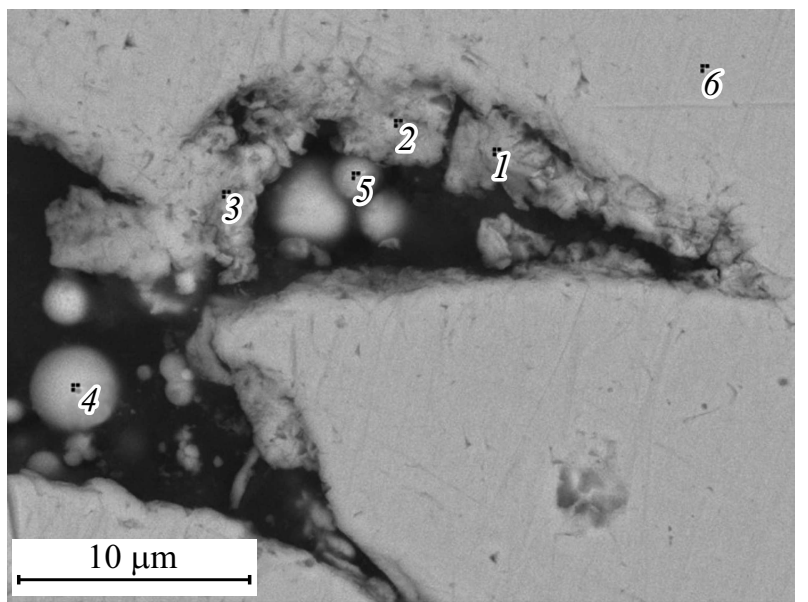

Рис. 3. Микроструктура стали 3 в полосе локализации деформации, элементный состав в областях, отмеченных цифрами, приведен в табл. 1. Пластина-ударник разгонялась зарядом литого тротила.

булярный цементит размером $0.03-0.06 \mu \mathrm{m}$ выделялся вдоль границы с ферритом. Сияющие (солнечные) частицы, как часто их называют в литературе, наблюдаются во многих исследованиях. По мнению авторов работы [4], яркие частицы могут быть результатом тонкой рекристаллизованной структуры.

Из рис. 3 следует, что в ПЛД протекают два разнонаправленных процесса: разложение цементита и повторное его образование. Увеличение амплитуды нагрузки свыше $15 \mathrm{GPa}$ изменяет микроструктуру в полосах локализации стального образца: практически весь перлит переходит в глобулярную форму, при этом глобулы цементита могут достигать размера $3 \mu \mathrm{m}$. Характерно, что вблизи внутренней границы деформационной полосы материал находится в пористом состоянии. На рис. 3 цифры 1-6 отмечают точки, для которых проведен микроспектральный анализ, представленный в табл. 1 (содержание элементов дано в массовых процентах), который показывает наличие высокого содержания углерода (точки 1-3), в то время как в самой сферической глобуле цементита (точка 4) содержание углерода соответствует формуле метастабильной фазе $\chi \mathrm{Fe}_{x} \mathrm{C}\left(\mathrm{Fe}_{3} \mathrm{C} \rightarrow \chi \mathrm{Fe}_{x} \mathrm{C}\right.$, где $\left.x<3\right)$ [4]. Интересно, что метастабильная фаза сохраняет кристаллическую решетку цементита, при этом состав ее меняется, и количество углерода может достигать 30 at.\%.

При изучении внешнего поверхностного слоя рядом с откольной трещиной в лучах отраженных электронов (метод материального контраста, Zeiss Ultra plus) было обнаружено, что прилегающий к ПЛД слой толщиной $30-40 \mu \mathrm{m}$ обеднен углеродом, в то время как сама деформационная полоса содержит избыток углерода. Наличие обедненного слоя свидетельствует о массопереносе углерода из матричного материала в область поврежденного металла. Высокое содержание углерода в
ПЛД отмечалось в работе [16]. Измеренная микротвердость в слое протяженностью около $50 \mu \mathrm{m}$ (с каждой стороны полосы) оказалась существенно ниже, чем внутри полосы и в исходном материале [7], что является подтверждением массопереноса углерода в сталях в процессе локализации деформации. Дополнительный приток углерода приводит к карбидизации феррита и перестройке структуры материала в ПЛД. Становится понятным, что обогащение перлита углеродом на рис. 3 является результатом миграции углерода к ПЛД, названным эффектом самозалечивания. Следует отметить, что традиционный переход пластинчатого в глобулярный цементит требует наличия высокой температуры и длительной выдержки в течение десятков часов.

\section{2. Окисление фрагментов в полосах локализации}

Из табл. 1 также следует, что вблизи внутренней границы ПЛД (точки 1-3 на рис. 3) обнаруживается высокое содержание кислорода. Рис. 4 демонстрирует наличие зародышей оксидов в ПЛД стального образца. Отдельные фрагменты металла оказались покрытыми ультратонкими частицами шишкообразного вида. Такой вид микроструктуры часто наблюдается в титане, алюминии и меди [6]. Размер зародышей оксида железа составляет $20-40 \mathrm{~nm}$.

Таблица 1. Микроспектральный анализ структуры стали 3

\begin{tabular}{c|r|r|r|c|c|c}
\hline Элемент & \multicolumn{1}{c|}{1} & \multicolumn{1}{c|}{2} & \multicolumn{1}{c|}{3} & 4 & 5 & 6 \\
\hline $\mathrm{C}$ & \multicolumn{1}{c|}{27.65} & 26.25 & 33.31 & 7.64 & 16.83 & 4.17 \\
\hline $\mathrm{O}$ & 6.31 & 6.90 & 8.32 & 1.02 & 19.78 & - \\
\hline $\mathrm{Al}$ & 1.25 & 1.17 & 0.98 & 0.25 & 0.88 & 0.85 \\
\hline $\mathrm{Fe}$ & 64.79 & 65.68 & 57.39 & 91.09 & 62.51 & 94.98
\end{tabular}

Примечание. Содержание элементов дано в массовых процентах. Цифры в первой строке соответствуют областям, показанным на рис. 3.

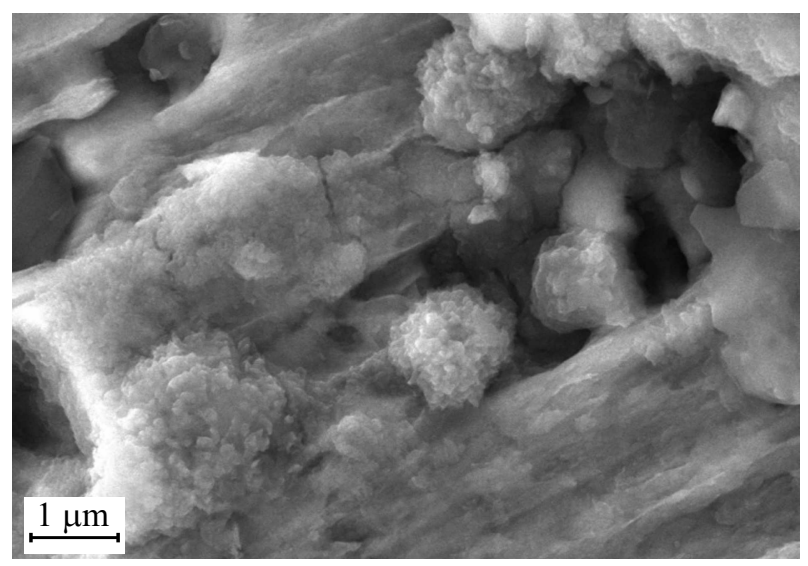

Рис. 4. Образование зародышей оксида железа на фрагментах внутри полосы локализации стального образца. 
Авторы работы [5] предположили, что в процессе высокоскоростной деформации кислород, растворенный в металле при его промышленном изготовлении, мигрирует из матричного материала к местам локализации пластической деформации. Кислород в металле может находиться в виде ионизированного, растворенного в кристаллической решетке железа, в виде атомов, адсорбированных на внутренних поверхностях раздела, или в виде молекул газа, заполняющего различные несплошности, существующие внутри металла. Перемещение и перераспределение газа внутри металлов может происходить путем диффузии (по междоузлиям кристаллической решетки, границам зерен и фаз и т.д.). В последние годы показано, что в неравновесных условиях (при пластической деформации) наблюдается изменение скорости диффузии [17]. Кислород может захватываться движущимися дислокациями и перемещаться вместе с ними.

\section{3. Массоперенос ультратонких частиц в процессе локализации}

Миграция атомов и ультратонких частиц оказалась явлением общего характера, которая сопровождает локализацию пластической деформации при ударных нагрузках. Ранее это явление наблюдалось на дисперсноупрочненном сплаве алюминия [6]. Скопление частиц интерметаллидов на берегах полос локализации свидетельствует о миграции ультратонких частиц упрочняющей фазы из матричного материала к местам повреждаемости. Толщина слоя, из которого поступали частички в область растущего разрушения, составляет $10-20 \mu \mathrm{m}$. Массоперенос частиц к ПЛД назван эффектом самозалечивания.

На рис. 5 приведена микроструктура ПЛД в двуфазном титановом сплаве Ti6A14V. Исходная структура $(\alpha+\beta)$ титанового сплава - пластинчатая. Внутри $\beta$-фазы образуются колонии из параллельных пластинок $\alpha$-фазы, сходные по внешнему виду с колониями перлита в стали. Толщина $\alpha$-пластин меняется от $0.2-0.7 \mu \mathrm{m}$,

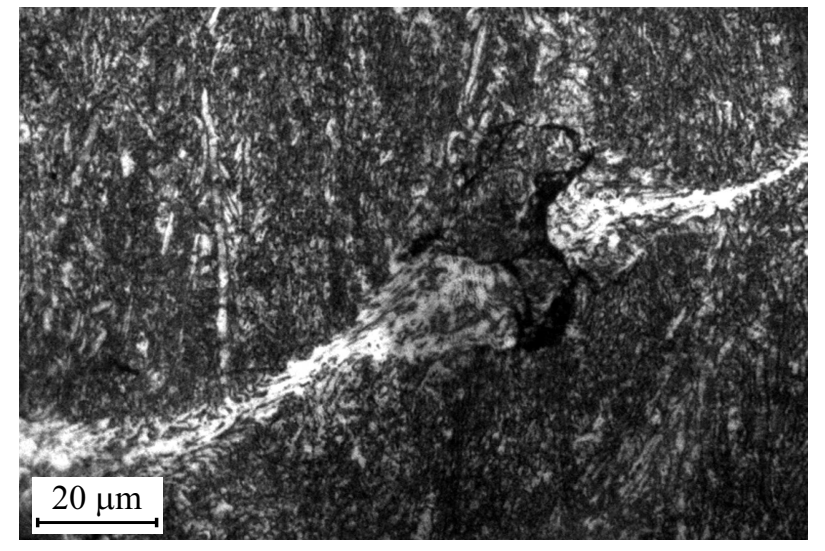

Рис. 5. Сегрегация частиц $\alpha$-фазы на местах откольной повреждаемости в двуфазном титановом сплаве. длина - от 5-8 $\mu \mathrm{m}$, а среднее расстояние между колониями - порядка $2 \mu \mathrm{m}$. Светлая более твердая $\alpha$-фаза вблизи ПЛД раздроблена и представлена в виде отдельных мелкодисперсных частиц. Сама полоса локализованной деформации покрыта множеством очень тонких нитей из $\alpha$-фазы. Внутри переплетения таких нитей можно обнаружить достаточно крупные частицы белой фазы, по размеру превышающие толщину $\alpha$-пластин. Более темные области рядом с ПЛД, обедненные частицами $\alpha$ фазы, не превышают 3-5 длине ПЛД. По сравнению с алюминиевым дисперсноупрочненным сплавом и сталью, область в двуфазном титановом сплаве, откуда ультратонкие частицы $\alpha$-фазы мигрировали к местам растущего нарушения сплошности, оказалась небольшой, не более $5 \mu \mathrm{m}$. Наличие значительного количества $\alpha$-фазы в ПЛД предполагает, что, возможно, имеет место дополнительный распад $\beta$ фазы в процессе деформации образца в стоячей волне. В результате сегрегации $\alpha$-фазы в зоне интерференции волн (ПЛД) происходит перераспределение фазового состава.

Следует отметить, что миграция легирующих элементов, растворение фаз внедрения и замещения при квазистатической холодной деформации хорошо известны [18-20]. Активизация низкотемпературного растворения достигается за счет генерации большого количества точечных и линейных дефектов, которые обладают повышенной диффузионной подвижностью в металлических матрицах и формируют ковалентную и ионную связи с атомами в частицах и матрицах, что является существенным фактором механизма твердофазных реакций.

Авторы [18-20] отмечают, что активное развитие процесса массопереноса совпадает с образованием областей некристаллографического сдвига с большой локальной деформацией и интенсивной генерацией дефектов кристаллической решетки в полосах локализации. Как показали исследования, растворение частиц при холодной деформации является неравновесным процессом. Равновесным в этих условиях является выделение частиц из пересыщенного твердого раствора, растворимость которого уменьшается с понижением температуры. Неравновесный процесс деформационного растворения частиц идет за счет дрейфа атомов в поле напряжения дислокаций, перерезающих частицу. Расстояние, на которое могут дрейфовать атомы, по оценке составляет 2-30 nm. Обращает на себя внимание, что во взрывных экспериментах массоперенос осуществлялся на расстояния, превышающие квазистатические на несколько порядков: углерод мигрирует на расстояния до $50 \mu \mathrm{m}$, а процесс глобулизации цементита в обычных условиях требует многих часов выдержки при высокой температуре, что на семь-восемь порядков больше, чем при импульсных нагрузках. Проблема аномально высоких скоростей массопереноса при динамических нагрузках дискутируется не одно десятилетие [10]. 


\section{2. Особенности ультразвуковой осцилляции в стоячих волнах при образовании продольных полос локализованной деформации}

\section{1. К вопросу о движущей силе потока частиц к зоне откольной повреждаемости}

Тепловое давление в твердом теле при нормальных условиях $(T=300 \mathrm{~K})$ за счет нагрева от $0 \mathrm{~K}$ равно $P_{T}=\gamma c_{V} \frac{\Delta T}{V_{0}}$, что составляет для железа $1.9 \mathrm{GPa}$, которое компенсируется упругим давлением той же величины [21], здесь $\gamma$ - коэффициент Грюнайзена, $c_{v}-$ теплоемкость, $\Delta T$ - температура нагрева. В ПЛД предельно допустимое растяжение близко к откольной прочности материала. Увеличение объема при этом определяется законом сохранения массы и равно $\Delta V / V_{0}=u_{s} / D$, где $D$ - скорость распространения ударной волны. Для стального образца критическая скорость составляет $u_{s}=112 \mathrm{~m} / \mathrm{s}$. Увеличение объема равно $2.3 \%$, что соответствует значению упругого давления $\Delta P_{x}=\frac{1}{\chi_{0}} \frac{\Delta V}{V}$, равному $3.8 \mathrm{GPa}$, здесь $\chi_{0}-$ изотермическая сжимаемость. Это та движущая сила, с которой материал будет стремиться привести атомы к равновесному состоянию, залечить растущую несплошность, приводя в движение поток „строительного“ материала, направленный к откольной повреждаемости.

\section{2. Образование дополнительных гармоник стоячей волны}

Эксперименты по изучению особенностей деформирования образца в режиме стоячей волны проводились по схеме, приведенной на рис. 1 (без обоймы), в качестве образца использовался толстостенный полый цилиндр. В данной постановке эксперимента характер повреждаемости образца определяется боковыми волнами разгрузки, интерференция которых образует в середине образца откольную (кольцевую) повреждаемость (трещину или ПЛД) в форме цилиндра. Такая форма образца удобна для приготовления шлифов, поскольку структура материала в любом сечении одинакова. Влияние боковых волн разгрузки на ударную волну в образце проявляется в искривлении фронта волны в области взаимодействия ее с разгрузкой и в снижении величины ее амплитуды. Авторы работы [22] показали, что ударная волна вдоль боковой поверхности перемещается стационарно (за счет наклонного положения) с постоянной скоростью, равной скорости ударно-сжатого материала с амплитудой в 1/4 начальной величины. В каждом сечении, через которое проходит ударная волна, грани образца приходят в движение и становятся источниками боковых волн разгрузки. Возникшая волна пересекает все сечение образца, отражается на противоположной грани волной сжатия и возвращается в исходное положение [10]. Отражение волн на свободной поверхности, где падающая волна взаимодействует со своей отраженной волной противоположного знака, приводит к смене характера отраженных волн: волна разгрузки становится волной сжатия и наоборот. Процесс отражения на свободной поверхности является необходимым механизмом осцилляции, поскольку меняет направление скорости граней образца на противоположное. Такой процесс повторяется многократно, пока циркуляция волн не затухнет. Период цикла равен $T=2 \delta / C$, где $\delta$ - толщина образца, $C$ - продольная скорость звука [8].

Зона интерференции отраженных от разных граней волн имеет ширину $2 b_{s_{0}}$, где $s_{0}=\frac{u_{0}}{c_{0}}-$ малый параметр, равный отношению массовой скорости $u_{0}$ к объемной скорости звука $c_{0}$; параметры $b$ и $c_{0}-$ коэффициенты в линейной зависимости скорости распространения фронта ударной волны от массовой скорости. На ширине зоны интерференции волн разгрузки скорости встречных волн компенсируются, и материал переходит в состоянии торможения. Ультразвуковые колебания твердого тела, которые возникают в результате взаимодействия волн между собой и отражения их на поверхностях, ограничивающих образец, протекают в форме стоячей волны, волны Лэмба [23]. Частицы в узлах неподвижны. Согласно откольной модели, локализации деформации ПЛД зарождаются в зоне интерференции волн разгрузки, т.е. в узле стоячей волны. Иными словами, ПЛД на фотографиях шлифов являются узлами стоячих волн. Точки с максимальной амплитудой - это пучности. Расстояние между двумя соседними узлами или пучностями равно половине длины стоячей волны $\lambda / 2$, равной толщине образца. В симметричной стоячей волне частицы среды то приближаются с двух сторон к узлу, то от него удаляются. В результате колебательного движения среды в узлах возникает резкое изменение плотности и напряжения, здесь имеет место периодическая смена циклов сжатие-разгрузка. Это условия, в которых зарождаются и эволюционируют полосы локализации.

Особенностью стоячих волн является отсутствие передачи энергии через узловые точки. В областях между пучностью и узлом энергия, которой обладают частицы, колеблющиеся между узлами, сохраняется и не обменивается с соседними областями [23], в результате чего деформирование образца в стоячей волне продолжается значительно дольше времени действия импульса нагрузки и после того, как ударная волна затухнет.

Рис. 6 демонстрирует стальной образец с исходной ферритно-перлитной структурой после взрывного нагружения. Следует обратить внимание на то, что откольная повреждаемость (трещина или ПЛД) образуется в недеформированном материале. Прохождение плоской ударной волны не вносит видимых изменений: размер и форма зерна сохраняются. При высоких скоростях нагружения плоской ударной волной [24] более $20 \mathrm{GPa}$ практически во всех металлах и сплавах образуются двойники. ПЛД не возникают в экспериментах с плоской ударной волной, они наблюдаются за искривленными 


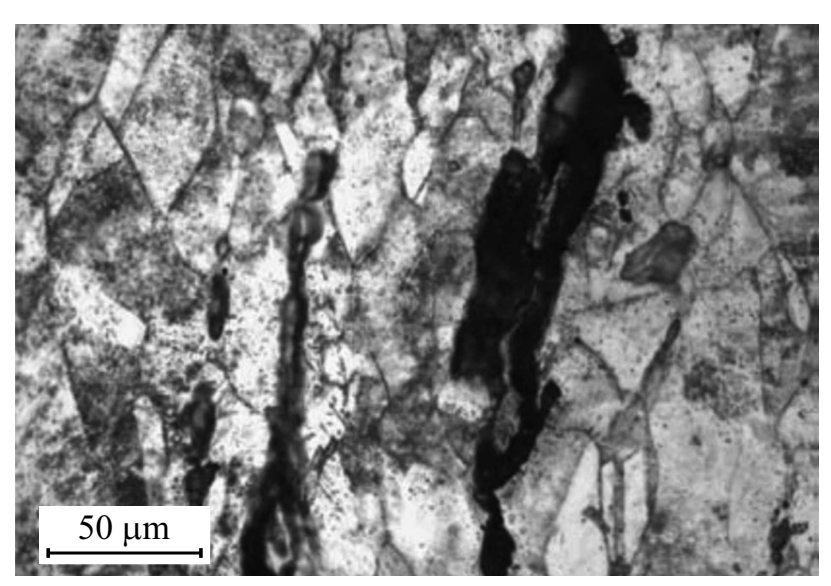

Рис. 6. Общий вид стального образца в форме цилиндра с исходной перлитоферритной структурой после ударного нагружения.

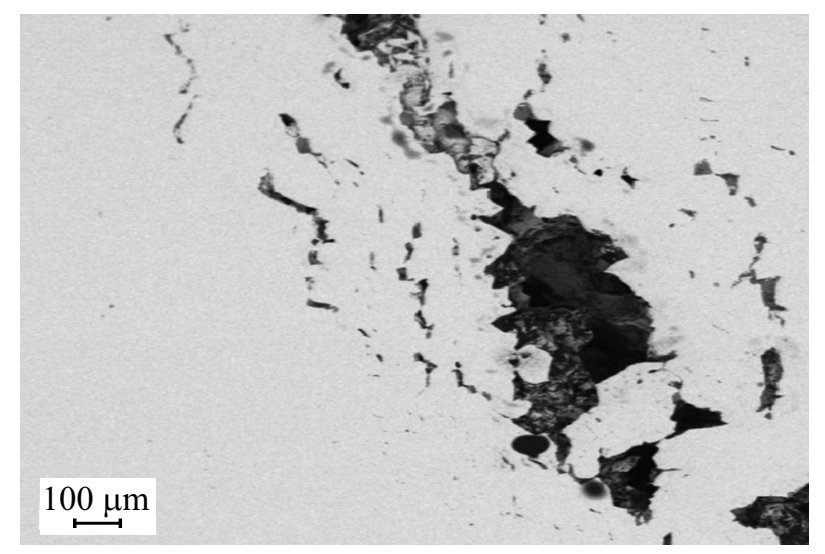

Рис. 7. Система обертонов вокруг откольной трещины в дюралюминиевом образце.

ударными волнами, например, в процессе проникания снаряда или кумулятивной струи в металл. При низкой энергии дефектов упаковки в образце возникает смесь деформационных двойников и полос локализации. Ширина полос менялась от 0.2 до $0.3 \mu \mathrm{m}$, а ширина микродвойников составляла $0.02 \mu \mathrm{m}$. Влияние боковых волн разгрузки в образцах ограниченных размеров состоит в том, что они изменяют форму фронта ударной волны, что приводит к образованию ПЛД, как видно из рис. 6. Появление не одной, а нескольких полос локализации является характерным свойством при образовании продольной повреждаемости под действием боковых волн разгрузки.

Рис. 7 демонстрирует общий вид образца дисперсноупрочненного алюминиевого сплава после нагружения пластиной-ударником. Обращает на себя внимание наличие центральной откольной трещины в середине образца и несколько более тонких полос локализации, окружающих ее. Центральная откольная трещина является ре- зультатом основного собственного колебания с частотой $\gamma=C / 2 \delta$ и длиной волны $\lambda$, равной $2 \delta$. Растягивающее напряжение в зоне интерференции волн (узел стоячей волны) оказалось выше откольной прочности материала, что привело к нарушению сплошности. Участок образца между узлом смещения и пучностью (грань образца) длинной $\lambda / 4=\delta / 2$ образует в стоячей волне энергетический „отсек“, который не обменивается энергией с соседними участками. Согласно работе [23], в этом „отсеке“ возможно возникновение новых собственных колебаний-обертонов, в которых соотношение между толщиной образца и длиной волны обертона описывается выражением $\delta / 2=n L_{n} / 4$, где $n=1,3,5 \ldots$ Случай $n=1$ относится к основному собственному обертону. Каждая ПЛД на рис. 6 и 7 является узлом своей стоячей волны со своей собственной частотой.

Заметим, что движение частиц в стоячей волне в каждом сечении образца ориентировано перпендикулярно к боковой грани образца. Волновая картина на продольных шлифах складывается из многих стоячих волн, возникающих в момент прохождения ударной волны через сечение, и показывает суммарную повреждаемость (полоса локализованной деформации), которая ориентирована параллельно боковым граням.

\section{3. Оценка времени затухания ультразвуковой осцилляции образца}

В стоячей волне максимальное смещение пульсирующей грани (пучности) является характеристикой интенсивности стоячей волны, которая для классического ультразвука составляет несколько десятков микрон [14]. Учитывая, что ПЛД возникает при напряжениях ниже откольной прочности $\sigma_{s}$, в работе для оценки скорости $u_{s}$ используется скорость, соответствующая откольной прочности $\sigma_{s}$, которая определяется из решения уравнения $u_{s}^{2}+\left(c_{0} / b\right) u_{s}-\sigma_{s} /\left(b \rho_{0}\right)=0, c_{0}$ и $b-$ параметры адиабаты. Максимальная амплитуда грани оценивается из условия, что за полупериод грань смещается на расстояние $l=u_{s} T / 2$, а за второй полупериод возвращается в исходное положение. Как показывает оценка, ультразвуковые колебания, возникающие при ударных нагрузках, относятся к мощному типу осцилляций (табл. 2).

В металлах и сплавах затухание ультразвука сложным образом зависит как от кристаллической структуры, так и от других параметров. Считается, что основными физическими механизмами, приводящими к затуханию ультразвука, являются поглощение и рассеяние энергии на неоднородностях среды [25]. Для углеродистых сталей, например, потери на поглощение и рассеяние значительно меньше, чем для малоуглеродистых сталей, из-за различия упругой анизотропии зерен феррита и перлита. Перлит представляет собой тонкодисперсную смесь $\mathrm{Fe}+\mathrm{Fe}_{3} \mathrm{C}$, и он рассеивает значительно слабее, чем отдельные зерна феррита. Периодическая смена 
Таблица 2. Характеристики стоячей волны

\begin{tabular}{c|c|c|c|c|c|c|c|c|c}
\hline Металл & $\sigma_{g}, \mathrm{GPa}$ & $\sigma_{y}, \mathrm{GPa}$ & $\sigma_{s}, \mathrm{GPa}$ & $C, \mathrm{~km} / \mathrm{s}$ & $u_{s}, \mathrm{~m} / \mathrm{s}$ & $T_{0}, \mu \mathrm{s}$ & $l, \mu \mathrm{m}$ & $\alpha$ & $t_{d} / T_{0}$ \\
\hline $\mathrm{Al}$ & 0.6 & 0.29 & 1.22 & 6.36 & 80.7 & 2.20 & 88.8 & 0.080 & 35.7 \\
\hline $\mathrm{Cu}$ & 0.16 & $\sim 0.08$ & 1.64 & 4.73 & 46.9 & 2.96 & 69.4 & 0.029 & 66.7 \\
\hline $\mathrm{Ti}$ & 2.0 & 0.92 & 3.5 & 6.15 & 145.0 & 2.28 & 165 & 0.075 & 35.6 \\
\hline $\mathrm{Fe}$ & 1.4 & 0.82 & 4.25 & 5.77 & 112.6 & 2.43 & 116 & 0.086 & 38.3
\end{tabular}

Примечание. $\sigma_{g}$ - предел упругости Гюгонио, $\sigma_{y}$ - динамический предел текучести, $\sigma_{s}-$ откольная прочность, $C-$ продольная скорость звука, $u_{s}$ - максимальная скорость отклонения грани, $T_{0}-$ период колебаний, $l-$ максимальное смещение грани за один период, $\alpha-$ доля удельной энергии, переходящей в тепло в процессе деформации образца, $t_{d} / T_{0}$ - безразмерное время осцилляции образца в области пластического деформирования.

направления движений частиц при осцилляции увеличивает поглощение звука, вызываемого гистерезисом. При больших амплитудах деформации коэффициент затухания в сталях значительно возрастает.

Вопрос о затухании осцилляции при ударных нагрузках не изучен. Оценить коэффициент затухания можно качественно, используя геометрическую интерпретацию законов сохранения, как это сделано в работе [26]. Из геометрического представления законов сохранения следует, что удельная энергия, переходящая в тепло, на $P-V$-диаграмме равна площади, ограниченной прямой Михельсона и изэнтропой нагрузки. Для идеальной упругопластической среды потеря энергии на единицу массы составляет $d=\frac{2 \sigma_{y}\left(\varepsilon-\varepsilon_{g}\right)}{3 \rho_{0}}$, здесь $\sigma_{y}-$ динамический предел текучести, $\varepsilon_{g}-$ степень деформации, соответствующая пределу упругости Гюгонио $\sigma_{g}, \rho_{0}-$ плотность металла [27]. Учитывая, что локализация деформации ограничивается откольной прочностью $\sigma_{s}$, долю энергии, переходящую в тепло, можно представить в виде $\alpha=2 \sigma_{y}\left(\sigma_{s}-\sigma_{g}\right) / 3 \sigma_{s}^{2}$. Полная энергия единицы массы $E$ на $P-V$-диаграмме равна площади прямоугольника $P\left(V_{0}-V\right)$, где $P-$ давление за фронтом ударной волны, а $V$ и $V_{0}$ - удельный объем ударносжатого и исходного материала. Изменение энергии $E$ во времени за период колебания в стоячей волне описывается выражением: $\frac{d E}{d t / T_{0}}=e=\alpha E$, откуда следует, что коэффициент затухания стоячей волны равен доле энергии, переходящей в тепло, деленной на период колебания $T_{0}$. Коэффициент затухания стоячей волны равен доли энергии, переходящей в тепло, деленной на период колебания $T_{0}$. Коэффициент затухания амплитуды стоячей волны равен половине энергетического коэффициента затухания. В табл. 2 приведены величины $\alpha$ для нескольких металлов. Время пластического деформирования образца до момента перехода к упругим колебаниям, отнесенное к периоду колебания, зависит от свойств материала и описывается выражением $t_{d} / T_{0}=\left[2 \ln \left(\sigma_{s} / \sigma_{y}\right)\right] / \alpha$. Переход осцилляции в режим сопровождается существенным снижением величины коэффициента затухания.

\section{3. Охлаждение полос локализации деформации}

Физико-химические процессы, протекающие в полосах локализации, зависят от температурного режима в них. Согласно общепринятой термомеханической модели локализации деформации, температура в ПЛД достаточно высока и может вызывать разупрочнение материала. Сомнение в тепловом разупрочнении высказано в работе [26] - время существования температуры $600^{\circ} \mathrm{C}$ в ПЛД шириной $1 \mu \mathrm{m}$ составляет $1-2 \mathrm{~ns}$ после прохождения фронта ударной волны. Аномально высокие скорости охлаждения (в диапазоне $10^{3}-10^{6} \mathrm{~K} / \mathrm{s}$ ) являются причиной формирования метастабильных структур и образования металлических стекол в зоне сварных швов при сварке взрывом [28].

Представляет интерес оценка особенностей температурного режима в ПЛД для откольной модели локализации. Ударная волна при давлениях 10-20 GPa является слабой, температура во фронте волны, как правило, не превышает $350^{\circ} \mathrm{C}$. Следующая за фронтом разгрузка снижает температуру ударно-сжатого вещества. Для большинства металлов остаточный нагрев не превышает $5-30^{\circ}$ C. ПЛД возникают за фронтом ударной волны, где ударно-сжатый материал претерпел разгрузку и находится при остаточной температуре. В процессе высокоскоростной деформации поглощение звуковой энергии при ультразвуковой осцилляции образца сопровождается нагревом полос локализации за счет диссипативных процессов. В качестве функции интенсивного внутреннего источника нагрева, который характеризует переход работы пластической деформации в тепло, принято выражение $g(x, t)=\left[600^{\circ} \exp \left(-\alpha t / T_{0}\right)\right] / t_{d} \mathrm{deg} / \mu \mathrm{s}$. Длительность работы источника ограничена временем пластической деформации образца $t_{d}$. В расчетах рассматривался образец, период осцилляции $T_{0}$ которого равен $1 \mu \mathrm{s}$. Время пластической деформации при $T_{0}=1 \mu \mathrm{s}$, характерного для откольных пластин, совершающих осцилляцию во время полета, по величине совпадает с безразмерным временем пластического деформирования образца, равным $t_{d} / T_{0}$. 
Таблица 3. Температура в центре полосы в момент отключения источника внутреннего нагрева

\begin{tabular}{c|c|c|c|c|c|c}
\hline Элементы & $t_{d}, \mu \mathrm{s}$ & $L=10 \mu \mathrm{m}$ & $L=20 \mu \mathrm{m}$ & $L=30 \mu \mathrm{m}$ & $L=40 \mu \mathrm{m}$ & $L=50 \mu \mathrm{m}$ \\
\hline $\mathrm{Al}$ & 35.7 & 30.60 & 32.43 & 35.60 & 40.34 & 46.99 \\
\hline $\mathrm{Cu}$ & 104 & 30.13 & 30.56 & 31.27 & 32.28 & 33.60 \\
\hline $\mathrm{Fe}$ & 38.3 & 33.05 & 43.70 & 69.55 & 128.10 & 213.91 \\
\hline $\mathrm{Ti}$ & 35.6 & 36.47 & 59.90 & 121.32 & 228.50 & 342.52
\end{tabular}

Примечание. $L$ - толщина полос локализованной деформации, $t_{d}-$ время пластической деформации образца. Начальный подогрев равен $350^{\circ} \mathrm{C}$.
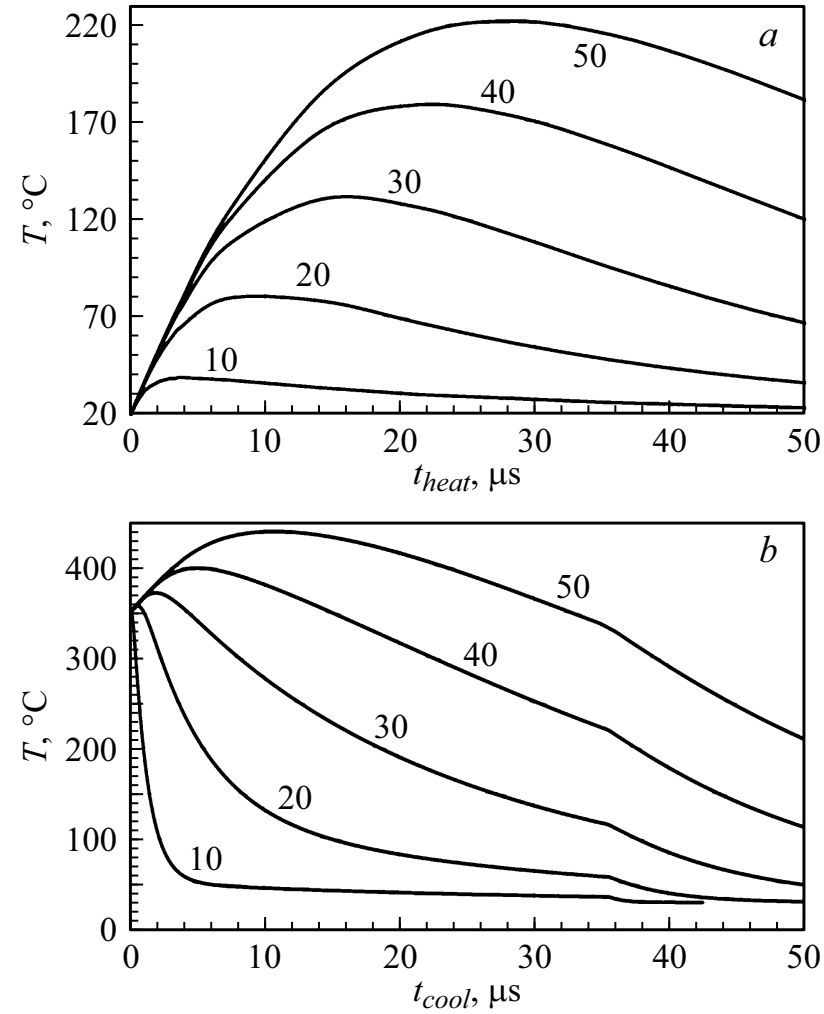

Рис. 8. Зависимость температуры в полосах локализации двуфазного титанового сплава в условиях конкуренции теплоотвода и работы источника внутреннего тепла: $a-$ при начальной остаточной температуре, $b-$ при начальном нагреве до $350^{\circ} \mathrm{C}$.

Неоднородное одномерное уравнение теплопроводности в частных производных вместе с краевыми и начальными условиями решалось числено в работе [29], при этом дифференциальное уравнение заменялось системой алгебраических уравнений. Для анализа ПЛД представлялась в виде пластины толщиной $L$, ограниченной параллельными плоскостями.

Рис. 8 демонстрирует температуру полос локализации в условиях конкуренции внутреннего нагрева и теплопроводности. Титановый сплав и сталь относятся к медленно остывающим металлам, и характеризуются более высоким ростом температуры в ПЛД по сравнению с медью и алюминиевым сплавом. Как следует из приведенного рисунка, максимальный подъем температуры значительно зависит от толщины ПЛД: чем толще полоса, тем больше тепла успевает накопиться в ее центральной части до момента прихода волны охлаждения к центру полосы локализации. В условиях конкуренции работа внутреннего источника нагрева заметно снижает скорость теплоотвода из ПЛД. Титановый сплав характеризуется наиболее высокой температурой нагрева по сравнению с другими металлами. Так, максимальная температура полосы локализации толщиной $50 \mu \mathrm{m}$ при нагреве от начальной температуры, близкой к остаточной, составляет $220^{\circ} \mathrm{C}$, в то время как для алюминиевого сплава - всего $65^{\circ} \mathrm{C}$. Несмотря на достаточно быстрое повышение температуры в начальный момент за счет перехода работы деформации в тепло, температура нагрева ПЛД от начальной комнатной температуры остается недостаточной, чтобы привести металл к разупрочнению, как ранее предполагалось в термомеханической модели локализации деформации.

Максимальный рост температуры ПЛД с предварительным подогревом до $350^{\circ} \mathrm{C}$, как видно из рис. $8, b$, составляет $100^{\circ} \mathrm{C}$, а в алюминиевом сплаве $-5^{\circ} \mathrm{C}$. Температура материала в ПЛД в момент окончания работы внутреннего источника тепла приведена в табл. 3 .

Быстрое охлаждение металла внутри полос локализации, размер которых не превышает нескольких десятков микрон, свидетельствует о том, что изменение фазового состава в ПЛД происходит в основном в результате холодной деформации.

\section{Заключение}

Структурные исследования позволили выявить, какие физико-химические процессы сопровождают формирование полос локализованной деформации. При динамических нагрузках не обнаружено каких-либо механизмов отклика (реакции) материала на деформирования, отличных от квазистатических, присущих только импульсному нагружению. Элементы внедрения (C, N,O) обладают повышенной диффузионной подвижностью в металлических матрицах, что является существенным для механизма твердофазных реакций. Температура нагрева за счет внутреннего источника, обязанного переходу работы деформации в тепло, незначительна и не может 
приводить материал к разупрочнению. Изменение фазового состава за счет протекающих физико-химических процессов в ПЛД происходит в основном в результате холодной деформации. Откольный характер образования полос локализованной деформации демонстрирует ведущую роль геометрии образца, поскольку грани являются источниками волн разгрузки. Поэтому понятны многочисленные попытки связать процесс возникновения ПЛД с физико-химическими характеристиками материала. Процесс осцилляции образца приводит к знакопеременному, длительному по сравнению с временем начального импульса сжатия, деформированию образца. Следствием процесса локализации деформации является массоперенос ультратонких частиц упрочняющей фазы и элементов внедрения из матричного материала к зоне повреждаемости, при этом расстояние миграции, проходимое частицами при импульсном нагружении, на несколько порядков выше, чем при квазистатических нагрузках за счет деформирования образца в режиме стоячих волн.

\section{Конфликт интересов}

Авторы заявляют, что у них нет конфликта интересов.

\section{Список литературы}

[1] В.Ф. Нестеренко, М.П. Бондарь. ФГВ, 30 (4), 99 (1994). [V.F. Nesterenko, M.P. Bondar'. Comb., Expl., Shock Waves, 30 (4), 500 (1994).]

[2] М.П. Бондарь. Физическая мезомеханика, 3 (6), 75 (2000). [M.P. Bondar'. Phys. Mesomechan. 3 (6), 75 (2000).]

[3] P.S. DeCarli, M.A. Meyers. In the book.: Shock waves and high-strain-rate phenomena in metals, ed. by M.A. Meyers, L.E. Murr (Plenum Press, NY., London, 1980), 341 p.

[4] M.A. Meyers, Y.B. Xu, Q. Xue, M.T. Perez-Prado, T.R. McNelley. Acta Mater., 51, 1307 (2003).

DOI: 10.1016/S1359-6454(02)00526-8

[5] Nai-Yong Tang, P. Niessen, R.J. Pick, M.J. Worswick. Mater. Sci. Eng., A, 131, 153 (1991).

DOI: $10.1016 / 0921-5093(91) 90391-Y$

[6] С.Н. Буравова. ЖТФ, $87(10), 1502$ (2017). DOI: $10.21883 /$ JTF.2017.10.44994.1927 [S.N. Buravova. Tech. Phys., 62 (10), 1509 (2017). DOI: $10.1134 / \mathrm{S} 1063784217100073$

[7] B. Hwang, S. Lee, Y.C. Kim, N.J. Kim, D.H. Shin. Mater. Sci. Eng., A, 441, 308 (2006). DOI: 10.1016/j.msea.2006.08.045

[8] С.Н. Буравова, Е.В. Петров, М.И. Алымов. ДАН, 469 (1), 34 (2016). DOI: 10.7868/S0869565216190099 [S.N. Buravova, E.V. Petrov, M.I. Alymov. Dokl. Phys., 61 (7), 309 (2016). DOI: 10.1134/S1028335816070016

[9] M. Hammerschmidt, H. Kreye. In the book: Shock waves and high-strain-rate phenomena in metals, ed. by M.A. Meyers, L.E. Murr (Plenum Press, NY., London, 1980), $961 \mathrm{p}$.

[10] С.Н. Буравова, Е.В. Петров. Химическая физика, 37 (2), 47 (2018). DOI: 10.7868/S0207401X18020073 [S.N. Buravova, E.V. Petrov. Rus. J. Phys. Chem. B, 12 (1), 120 (2018). DOI: $10.1134 / \mathrm{S} 1990793118010153$
[11] С.Н. Буравова, Ю.А. Гордополов. ДАН, 417 (6), 756 (2007). [S.N. Buravova, Yu.A. Gordopolov. Dokl. Phys., 52 (12), 666 (2007). DOI: 10.1134/S1028335807120063

[12] А.Ф. Беликова, С.Н. Буравова, Ю.А. Гордополов. ЖТФ, 83 (2), 153 (2013). [A.F. Belikova, S.N. Buravova, Yu.A. Gordopolov. Tech. Phys., 58 (2), 302 (2013). DOI: $10.1134 / \mathrm{S} 1063784213020035$

[13] А.Ф. Беликова, С.Н. Буравова,Е.В. Петров. ЖТФ, 83 (8), 68 (2013). [A.F. Belikova, S.N. Buravova, E.V. Petrov. Tech. Phys., 58 (8), 1152 (2013). DOI: 10.1134/S1063784213080057

[14] А.В. Кулемин. Ультразвук и дифбузия в металлах (Металлургия, М., 1978)

[15] В.Г. Гаврилюк, Д.С. Герцрикен, Ю.А. Полушкин, B.M. Фальченко. ФММ, 51 (1), 147 (1981). [V.G. Gavrilyuk, D.S. Gertsriken, Yu.A. Polushkin, V.M. Fal'chenko. Phys. Metals Metal Sci., 51 (1), 147 (1981).]

[16] C.L. Wittman, M.A. Meyers, H.R. Pak. Metall. Trans. A, 21A, 707 (1990).

[17] О.Л. Хасанов, Э.С. Двилис, В.В. Полисадова, А.П. Зыкова. Эффекты мощного ультразвукового воздействия на структуру и свойства наноматериалов: учебное пособие. (Изд-во Томского политех. ун-та, Томск, 2008)

[18] А.Р. Кузнецов, В.В. Сагарадзе. ФММ, 93 (5), 13 (2002). [A.R. Kuznetsov, V.V. Sagaradze. Phys. Metals Metal Sci., 93 (5), 13 (2002).]

[19] С.Н. Фаизова, Г.И. Рааб, Н.Г. Зарипов, Д.А. Аксенов, И.А. Фаизов. Физическая мезомеханика, 18 (4), 87 (2015). [S.N. Faizova, G.I. Raab, N.G. Zaripov, D.A. Aksenov, I.A. Faizov. Phys. Mesomechan., 18 (4), 87 (2015).]

[20] В.А. Шабашов. Вопросы материаловедения, 55 (3), 169 (2008). [V.A. Shabashov. Mater. Sci., 55 (3), 169 (2008).]

[21] Я.Б. Зельдович, Ю.П. Райзер. Физика ударных волн и высокотемпературных гидродинамических явлений (Физматгиз, М., 1963)

[22] А.А. Гриб, А.Г. Рябинин, С.А. Христианович. ПММ, 20 (4), 532 (1956). [A.A. Grib, A.G. Ryabinin, S.A. Khristianovich. Appl. Mathem. Mechan., 20 (4), 532 (1956).]

[23] Г.С. Горелик. Колебания и волны. Введение в акустику, радиофизику и оптику (Изд-во физ.-матем. лит-ры, М., 1959)

[24] L.E.Murr, E.V. Esquivel. J. Mater. Sci., 39 (4), 1153 (2004).

[25] Л.Г. Меркулов. ЖТФ, 27 (5), 1387 (1957). [L.G. Merkulov. Tech. Phys., 27 (5), 1387 (1957).]

[26] D.E. Grady, J.R. Asay. J. Appl. Phys. 53 (11), 7350 (1982). DOI: $10.1063 / 1.330101$

[27] Г.В. Степанов. Упруго-пластическая деформация материала под действием импульсных нагрузок (Наукова думка, Киев, 1979)

[28] И.А. Батаев, Д.В. Лазуренко, Ю.Н. Малютина, А.А. Никулина, А.А. Батаев, О.Э. Матц, И.Д. Кучумова. ФГВ, 54 (2), 122 (2018). DOI: 10.15372/FGV20180213 [I.A. Bataev, D.V. Lazurenko, Yu.N. Malyutina, A.A. Nikulina, A.A. Bataev, O.E. Mats, I.D. Kuchumova. Comb. Expl. Shock Waves, 54 (2), 238 (2018). DOI: 10.1134/S0010508218020132

[29] Г.В. Кузнецов, М.А. Шеремет. Разностные методы решения задач теплопроводности: учебное пособие (Изд-во Томского политех. ун-та, Томск, 2007) 